LA W RENCE LIVERM ORE N A TIONAL LABORATORY
Hydrodynamic Modeling of Air Blast Propagation from the Humble Redwood Chemical High Explosive Detonations Using GEODYN

V. D. Chipman

September 26, 2011 
This document was prepared as an account of work sponsored by an agency of the United States government. Neither the United States government nor Lawrence Livermore National Security, LLC, nor any of their employees makes any warranty, expressed or implied, or assumes any legal liability or responsibility for the accuracy, completeness, or usefulness of any information, apparatus, product, or process disclosed, or represents that its use would not infringe privately owned rights. Reference herein to any specific commercial product, process, or service by trade name, trademark, manufacturer, or otherwise does not necessarily constitute or imply its endorsement, recommendation, or favoring by the United States government or Lawrence Livermore National Security, LLC. The views and opinions of authors expressed herein do not necessarily state or reflect those of the United States government or Lawrence Livermore National Security, LLC, and shall not be used for advertising or product endorsement purposes.

This work performed under the auspices of the U.S. Department of Energy by Lawrence Livermore National Laboratory under Contract DE-AC52-07NA27344. 


\title{
Hydrodynamic Modeling of Air Blast Propagation from the Humble Redwood Chemical High Explosive Detonations Using GEODYN
}

\author{
Veraun Chipman \\ Structural and Applied Mechanics \\ Engineering Technologies Division \\ Lawrence Livermore National Laboratory \\ Livermore, CA 94551, USA
}

\begin{abstract}
Two-dimensional axisymmetric hydrodynamic models were developed using GEODYN to simulate the propagation of air blasts resulting from a series of high explosive detonations conducted at Kirtland Air Force Base in August and September of 2007. Dubbed Humble Redwood I (HR-1), these near-surface chemical high explosive detonations consisted of seven shots of varying height or depth of burst. Each shot was simulated numerically using GEODYN. An adaptive mesh refinement scheme based on air pressure gradients was employed such that the mesh refinement tracked the advancing shock front where sharp discontinuities existed in the state variables, but allowed the mesh to sufficiently relax behind the shock front for runtime efficiency. Comparisons of overpressure, sound speed, and positive phase impulse from the GEODYN simulations were made to the recorded data taken from each HR-1 shot. Where the detonations occurred above ground or were shallowly buried (no deeper than $1 \mathrm{~m}$ ), the GEODYN model was able to simulate the sound speeds, peak overpressures, and positive phase impulses to within approximately $1 \%, 23 \%$, and $6 \%$, respectively, of the actual recorded data, supporting the use of numerical simulation of the air blast as a forensic tool in determining the yield of an otherwise unknown explosion.
\end{abstract}

\section{Introduction}

Determining the yield and height or depth of burst of an explosive detonation posteriori, whether it be nuclear, chemical, or mechanical are essential to forensic analysis of explosions. It's postulated that both the magnitude and positive phase impulse of the air blast (i.e. the integration of the overpressure time-history curve over the first positive pulse), coupled with the recorded seismic ground motions from the detonation could be used to determine the yield, and height or depth of burst of an explosion. LLNL is developing a tool to do just that. As part of that ongoing effort, the feasibility of using air blast data was partially investigated here by determining the adequacy to which a hydrodynamic modeling code, such as GEODYN, could simulate an actual explosive air blast. Other factors such as buildings, terrain, wind, and air temperature affect the air blast data recorded at some remote sensor. These factors were not investigated here, but some insights as to their effects are given in Marrs et al. (2009).

\section{Humble Redwood I Configurations}

In August and September of 2007, a series of high explosive detonations was conducted at Kirtland Air Force Base. Dubbed Humble Redwood I (HR-1) and documented in Foxall et al. 
(2011), these high explosive detonations consisted of seven shots of varying height or depth of burst. Each shot contained $1450 \mathrm{lbs}$ of ammonium nitrate and fuel oil (ANFO) that produced an explosive yield of approximately 0.54 tons of TNT. The ANFO and pentolite or C-4 boosters were encased in cylindrical Sonotubes that had radii and heights of 0.91 and 1.22 meters, respectively. There were four above ground and three buried shots ranging from $+/-5$ meters from ground surface. Each shot was instrumented with multiple seismic and air pressure sensors, including Validyne pressure transducers installed by the Defense Threat Reduction Agency (DTRA) with an intended range of approximately 250 meters from ground zero. The Validyne sensors measured differential pressure across a diaphragm and had a low enough frequency response to capture the positive phase impulse of the air blast. Table 1 summarizes the HR-1 series of shots as well as the actual range between the Validyne pressure transducer and ground zero for each shot.

Table 1: HR-1 Shot Series

\begin{tabular}{|c|c|c|c|}
\hline Shot & $\begin{array}{c}\text { Height or Depth } \\
\text { Of Burst }\end{array}$ & $\begin{array}{c}\text { Range to } \sim 250 \text { m } \\
\text { Pressure Sensor }\end{array}$ & $\begin{array}{c}\text { DTRA Validyne } \\
\text { Pressure Data? }\end{array}$ \\
\hline $\mathrm{A}$ & $\mathrm{HOB}=5 \mathrm{~m}$ & $266 \mathrm{~m}$ & No \\
\hline $\mathrm{B}$ & $\mathrm{HOB}=3 \mathrm{~m}$ & $278 \mathrm{~m}$ & Yes \\
\hline $\mathrm{C}$ & $\mathrm{HOB}=1.5 \mathrm{~m}$ & $275 \mathrm{~m}$ & Yes \\
\hline $\mathrm{D}$ & $\mathrm{DOB}=1.5 \mathrm{~m}$ & $277 \mathrm{~m}$ & Yes \\
\hline $\mathrm{E}$ & $\mathrm{HOB}=0.5 \mathrm{~m}$ & $287 \mathrm{~m}$ & Yes \\
\hline $\mathrm{F}$ & $\mathrm{DOB}=0.5 \mathrm{~m}$ & $263 \mathrm{~m}$ & Yes \\
\hline $\mathrm{G}$ & $\mathrm{DOB}=5 \mathrm{~m}$ & $290 \mathrm{~m}$ & Yes \\
\hline
\end{tabular}

\section{Environmental and Geologic Conditions}

The site of the HR-1 detonations was relatively flat, as seen in Figure 1. Figure 2 is a depiction of the geology of the site. Due to the complexity in meshing introduced by the right leaning fault that outcrops at the far east end of the site, only the geology to the west of the ground-zero was modeled in this effort. This allowed the domain to be depicted using a two-dimensional cylindrical (r-z) mesh as described in a subsequent section. The environmental conditions at the time of each shot are given in Table 2. Of particular importance to this study is the air pressure and temperature as it directly affects the speed of sound and hence the propagation speed of the blast wave.

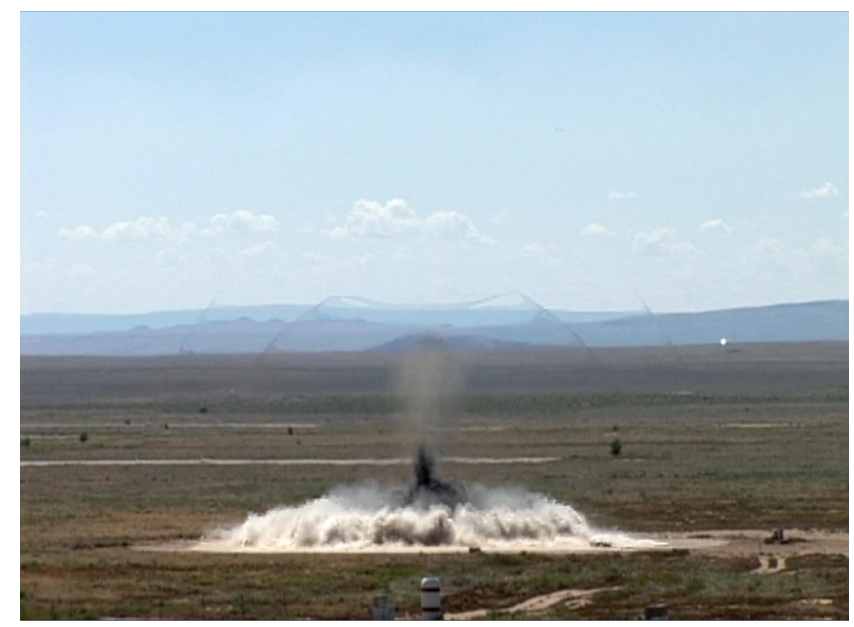

Figure 1: Photograph of Shot $\mathrm{E}$ at approximately $40 \mu \mathrm{s}$ after detonation. Taken from Marrs et al. (2009). 


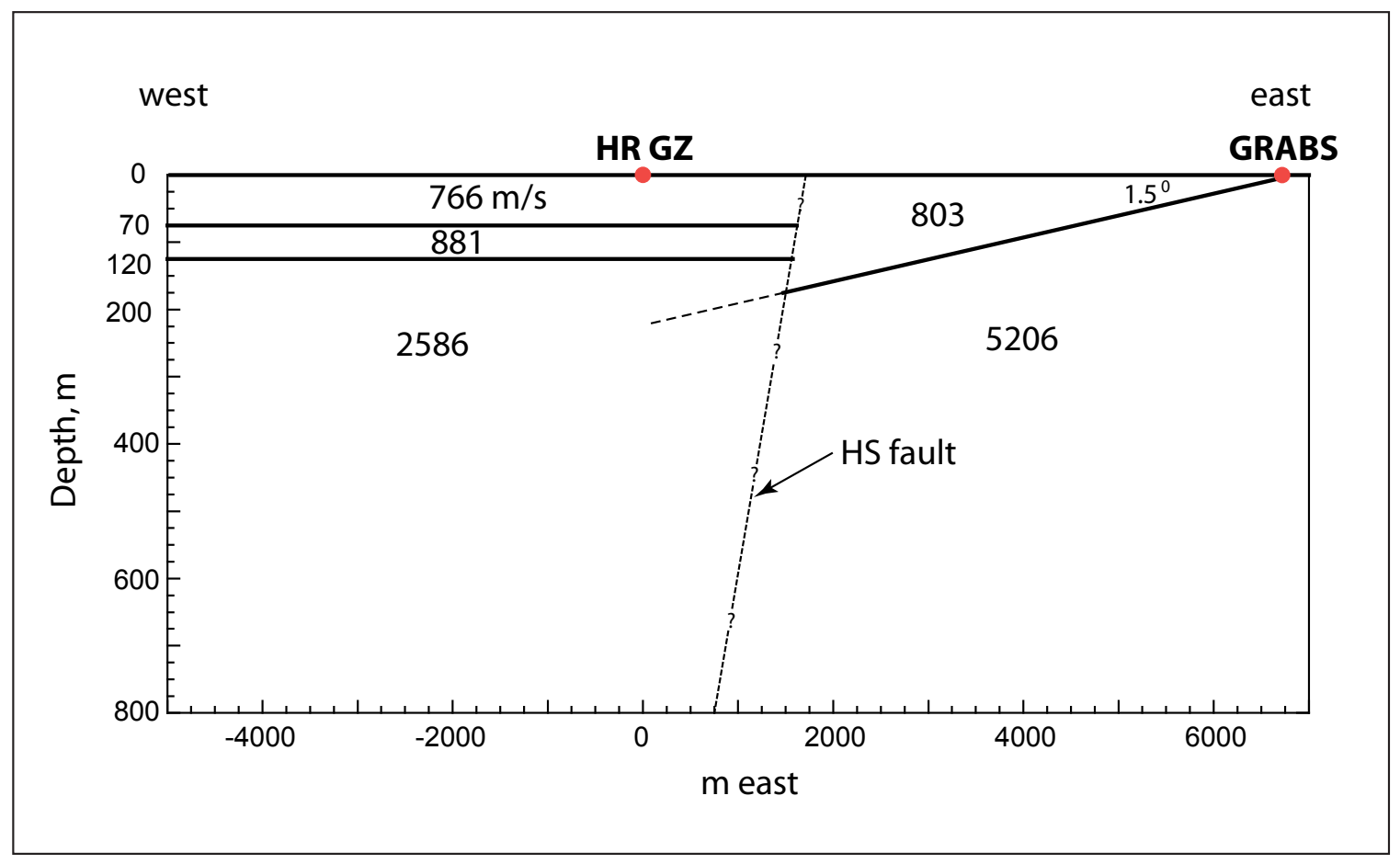

Figure 2: West-east seismic geology and velocity profile through the HR I ground-zero location. Vertical exaggeration is 7:1. Taken from Foxall et al. (2011).

Table 2: HR-1 Environmental Conditions

\begin{tabular}{|c|c|c|c|c|c|}
\hline Shot & $\begin{array}{c}\text { Temperature } \\
\left({ }^{\circ} \mathbf{F}\right)\end{array}$ & $\begin{array}{c}\text { Wind } \\
(\mathbf{m p h} @ \mathbf{a} \text { degrees) }\end{array}$ & $\begin{array}{c}\text { Relative } \\
\text { Humidity } \\
(\mathbf{\%})\end{array}$ & $\begin{array}{c}\text { Barometric } \\
\text { Pressure } \\
(\mathbf{i n H g})\end{array}$ & $\begin{array}{c}\text { Dew Point } \\
\left({ }^{\circ} \mathbf{F}\right)\end{array}$ \\
\hline A & 88.5 & $7.6 @ 238.2$ & 23.7 & 24.6 & 46.8 \\
\hline B & 79.8 & $4.9 @ 320.9$ & 34.6 & 24.8 & 49.4 \\
\hline C & 89.1 & $9.8 @ 309.6$ & 22.4 & 24.7 & 45.8 \\
\hline D & 74 & $4.9 @ 176.4$ & 51.7 & 25.0 & 55.1 \\
\hline E & 81.2 & $1.5 @ 198.1$ & 37.4 & 24.9 & 52.8 \\
\hline F & 78 & $4.4 @ 229$ & 46 & 24.8 & 55.1 \\
\hline G & 85 & $11 @ 200$ & 33 & 24.8 & 52.8 \\
\hline
\end{tabular}

\section{GEODYN Model Description}

GEODYN is a multidimensional, multiphysics, parallel, Eulerian adaptive mesh refinement (AMR) code. It includes multi-fluid hydrodynamics with real equation-of-state (EOS) behavior and solid material mechanics such elastic-plastic strains and deformations in geologic media. GEODYN was chosen for its capability to accurately model the physics of a propagating blast/shock wave in the atmosphere coupled with the seismic/mechanical response of the underlying geologic materials to an explosive detonation.

\section{Input and Explosive Source Parameters}

The atmosphere is modeled using constant parameters and the standard equation-of-state. Since the subsurface response is not the focus of this report, the reader is directed to Foxall et al. (2011) and Vorobiev (2008) for the model parameters and functions used for the layered alluviums. 
The yield was calculated as follows:

$$
\text { yield }=\rho \cdot \mathrm{vol} \cdot e_{0}
$$

where

yield $=$ explosive energy in $\mathrm{kJ}$ or tons of TNT where 1 ton of TNT $=4.184 \times 10^{9} \mathrm{~J}$

$\rho=$ density of the explosive source in $\mathrm{kg} / \mathrm{m}^{3}$

$\mathrm{vol}=$ volume of the explosive source in $\mathrm{m}^{3}$ (cylindrical in this case)

$e_{0}=$ specific energy of the explosive source in $\mathrm{kJ} / \mathrm{kg}$

The source parameters for the HR-1 series of detonations were calculated using the numerical code CHEETAH and calibrated to test data. Table 3 summarizes the explosive source parameters, and also includes the yield parameters for the SHAMRC modeling conducted by Marrs et al. (2009). There was about a 7.4\% difference in the yield calculated from the CHEETAH calibrations to the yield used in the SHAMRC modeling Mars et al. (2009). This is due to the inherent uncertainty in exactly quantifying the material properties of the chemical explosive.

Table 3: Explosive Source Parameters for GEODYN and SHAMRC Models

\begin{tabular}{|c|c|c|}
\hline $\begin{array}{c}\text { Explosive Source } \\
\text { Parameters }\end{array}$ & GEODYN & SHAMRC \\
\hline Density & $820 \mathrm{~kg} / \mathrm{m}^{3}$ & $829 \mathrm{~kg} / \mathrm{m}^{3}$ \\
\hline Radius & $0.4572 \mathrm{~m}$ & $0.455 \mathrm{~m}$ \\
\hline Height & $1.2192 \mathrm{~m}$ & $1.22 \mathrm{~m}$ \\
\hline Mass & $\begin{array}{c}656.5 \mathrm{~kg} \\
(1447 \mathrm{lbm})\end{array}$ & $\begin{array}{c}657.7 \mathrm{lb} \\
(1450 \mathrm{lbm})\end{array}$ \\
\hline Specific Energy & $3723.45 \mathrm{~kJ} / \mathrm{kg}$ & $3434.20 \mathrm{~kJ} / \mathrm{kg}$ \\
\hline Yield & $\begin{array}{c}2.445 \times 10^{6} \mathrm{~kJ} \\
(0.58 \text { tons of TNT })\end{array}$ & $\begin{array}{c}2.2594 \times 10^{6} \mathrm{~kJ} \\
(0.54 \text { tons of TNT })\end{array}$ \\
\hline
\end{tabular}

\section{Mesh Refinement Scheme}

For this modeling effort, a 2-d layered cylindrical mesh was used with an adaptive mesh refinement scheme. As shown previously in Figure 2, a constant atmospheric layer was used above layered alluviums. The atmospheric layer was 250 meters in height, while the layered alluviums went to a depth of 750 meters below the ground surface. The domain in its entirety was 1000 meters in radius by 1000 meters in height or the z-direction. At a radius of 0 meters, a symmetry boundary condition was employed. At the other edges of the domain, open flow boundaries were used.

Developing an appropriate mesh refinement scheme first involved determining a cell size that leveraged the scale of the physics involved with computational efficiency. A cell size of 1 meter in radius by 1 meter in height (z-direction) was deemed sufficient. The next step in developing the mesh refinement scheme was to determine the level of mesh refinement needed. Four different levels were explored:

1. No mesh refinement.

2. A $1 \times 4$ scheme where a 1 meter $\times 1$ meter cell was divided one time by 4 to give sub-cells that were 0.25 meters $\times 0.25$ meters. 
3. A $2 \times 4$ scheme where the 1 meter $\times 1$ meter cell was divided two times by 4 to give subcells that were 0.25 meters $\times 0.25$ meters and sub-sub-cells that were 0.0625 meters $\times$ 0.0625 meters.

4. A $3 \times 4$ scheme where the 1 meter $\times 1$ meter cell was divided three times by 4 to give subcells that were 0.25 meters $\times 0.25$ meters, sub-sub-cells that were 0.0625 meters $\times 0.0625$ meters, and sub-sub-sub-cells that were 0.015625 meters $\times 0.015625$ meters.

The sensitivity of the subsurface seismic response to changes in mesh refinement was found to be more pronounced than that of the atmospheric pressure response. Therefore, the vertical velocities in the subsurface for the deepest buried shot (Shot $\mathrm{G}$ ) were used to determine an appropriate level of mesh refinement. As shown in Figure 3, significant gains in accuracy were observed by going from no mesh refinement to the $1 \times 4$ level, and from the $1 \times 4$ level to the $2 \times 4$ level. Less gain was observed going from the $2 \times 4$ level to the $3 \times 4$ level. Thus, the $2 \times 4$ was deemed sufficient.

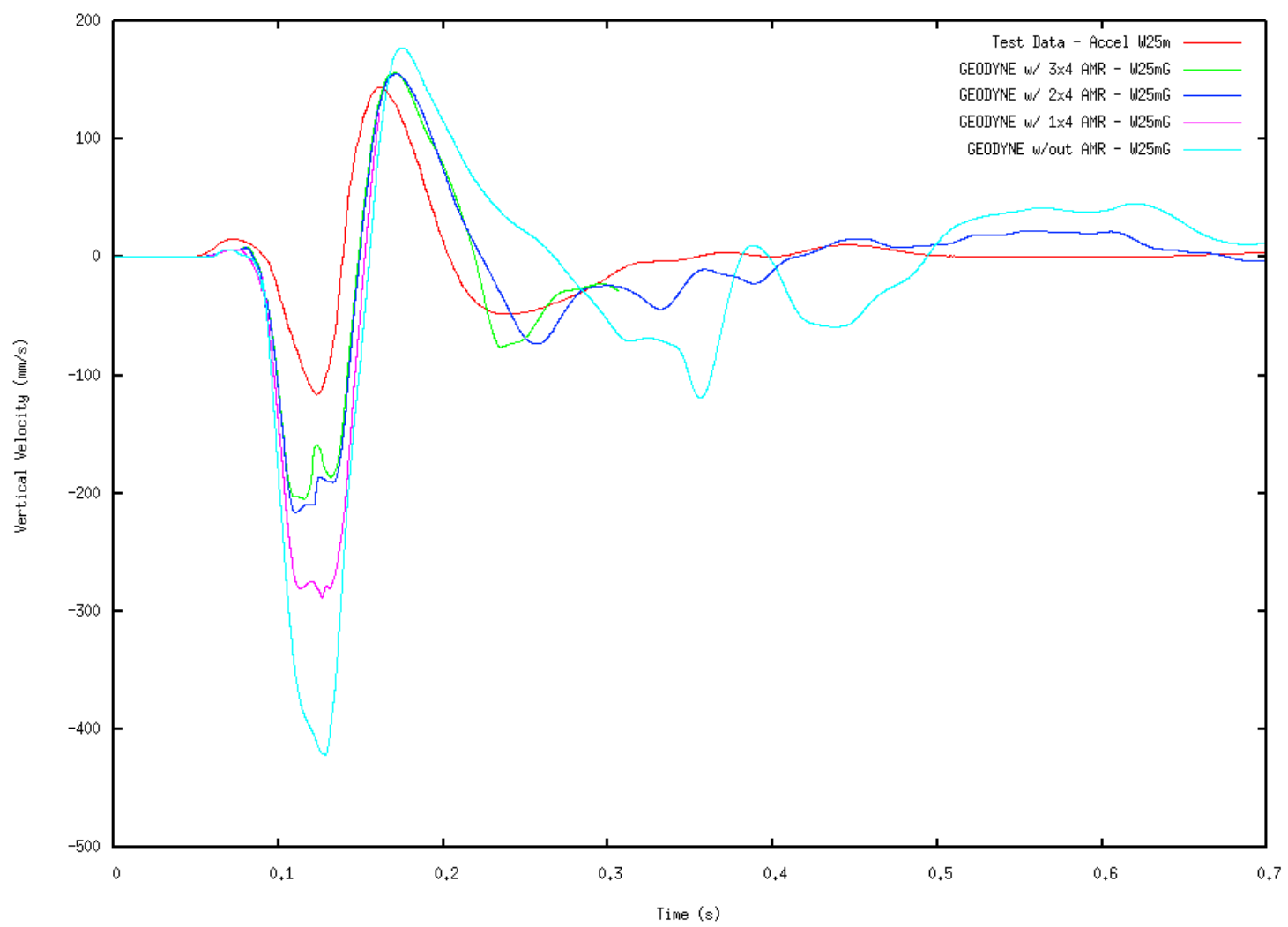

Figure 3: Plot of vertical velocity $(\mathrm{mm} / \mathrm{s}$ ) versus time (s) out to $0.7 \mathrm{~s}$ for Shot G comparing the near-field vertical velocity data taken from station W25m to GEODYN results for four models with varying levels of mesh refinement that range from no refinement to 3 levels of refinement.

The final step in the determining an appropriate mesh refinement scheme was to determine the physical parameters that would trigger the refinement and the level of relaxation. In the alluvium layers of the subsurface, mesh refinement was triggered using velocity magnitudes. In the atmosphere, the mesh was refined based on pressure gradients such that the mesh refinement tracked the advancing shock front where sharp discontinuities existed in the state variables, but allowed the mesh to relax behind the shock front for runtime efficiency. The following figures show the mesh refinement in the atmospheric layer at four progressive time steps during a model 
run. These figures illustrate how the mesh is refined around the propagating shock front where the pressures are most discontinuous, indicated by the "blackened" regions, as well as how the mesh relaxes to the base mesh size behind the advancing shock front.

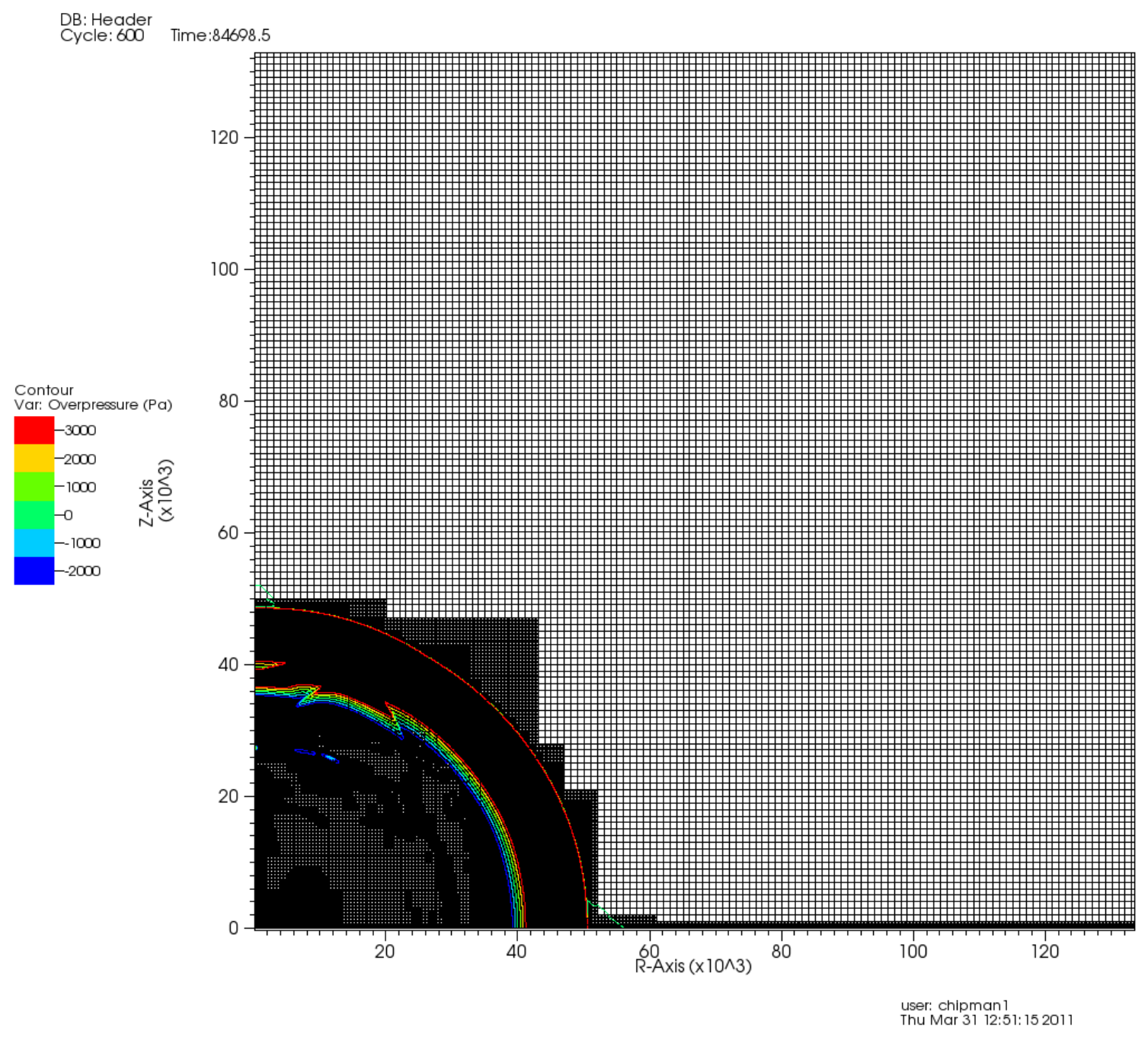

Figure 4: Mesh refinement for the HR-1 GEODYN model at Time $=0.0846985 \mathrm{~s}$. The "blackened" area represents the highest level of mesh refinement. 


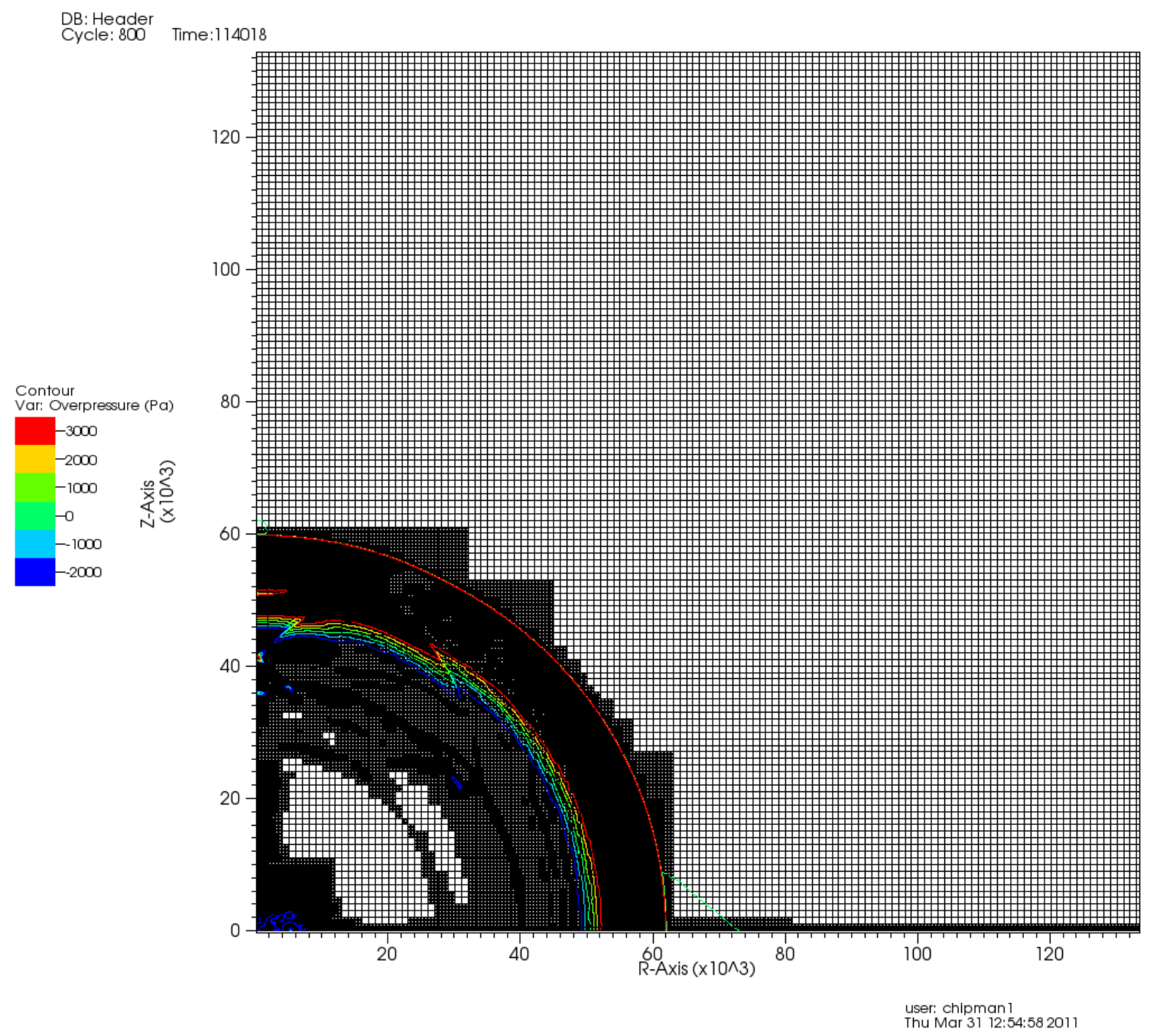

Figure 5: Mesh refinement for the HR-1 GEODYN model at Time $=0.114018 \mathrm{~s}$. The "blackened" area represents the highest level of mesh refinement. 


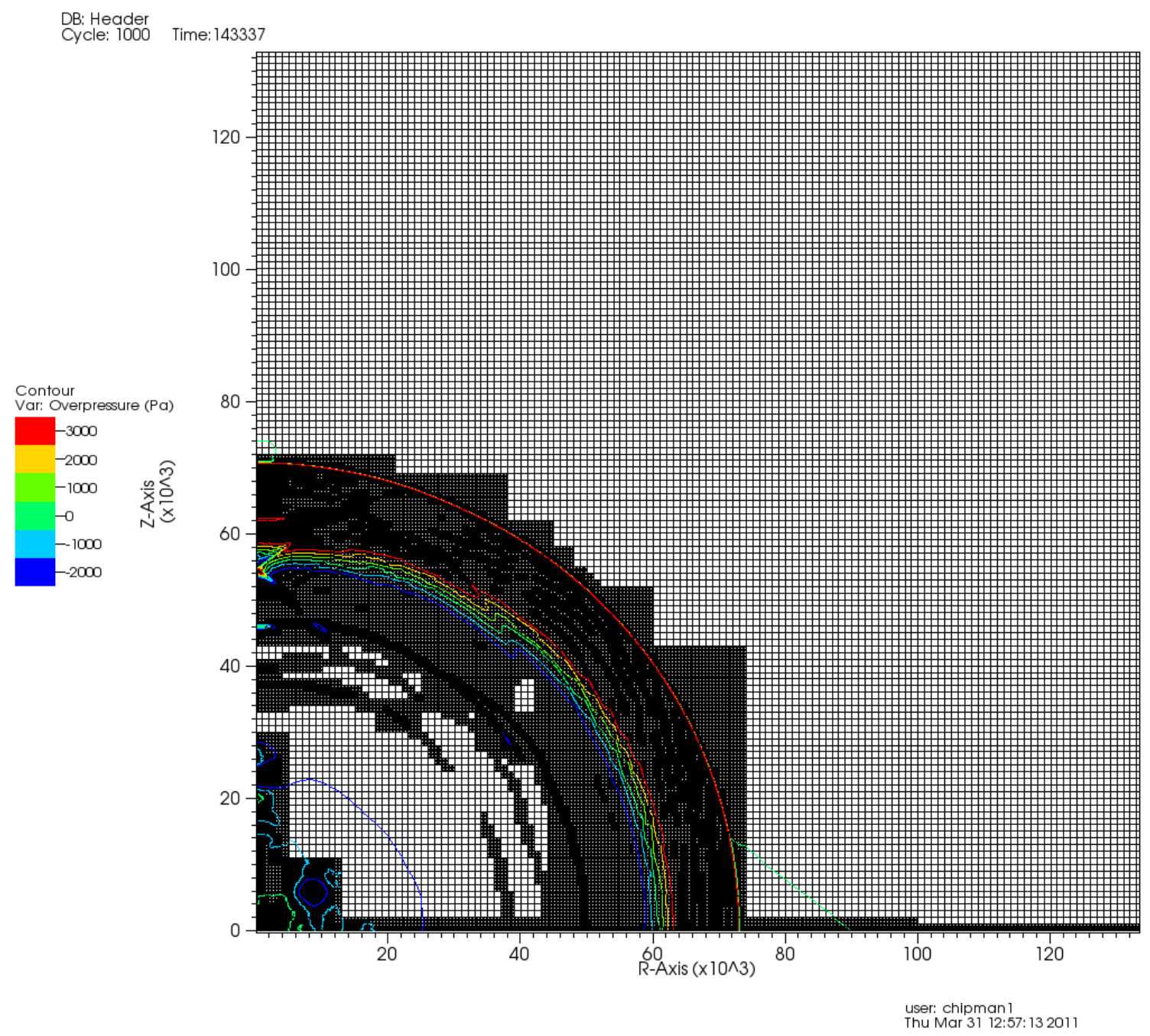

Figure 6: Mesh refinement for the HR-1 GEODYN model at Time $=0.143337$ s. The "blackened" area represents the highest level of mesh refinement. 


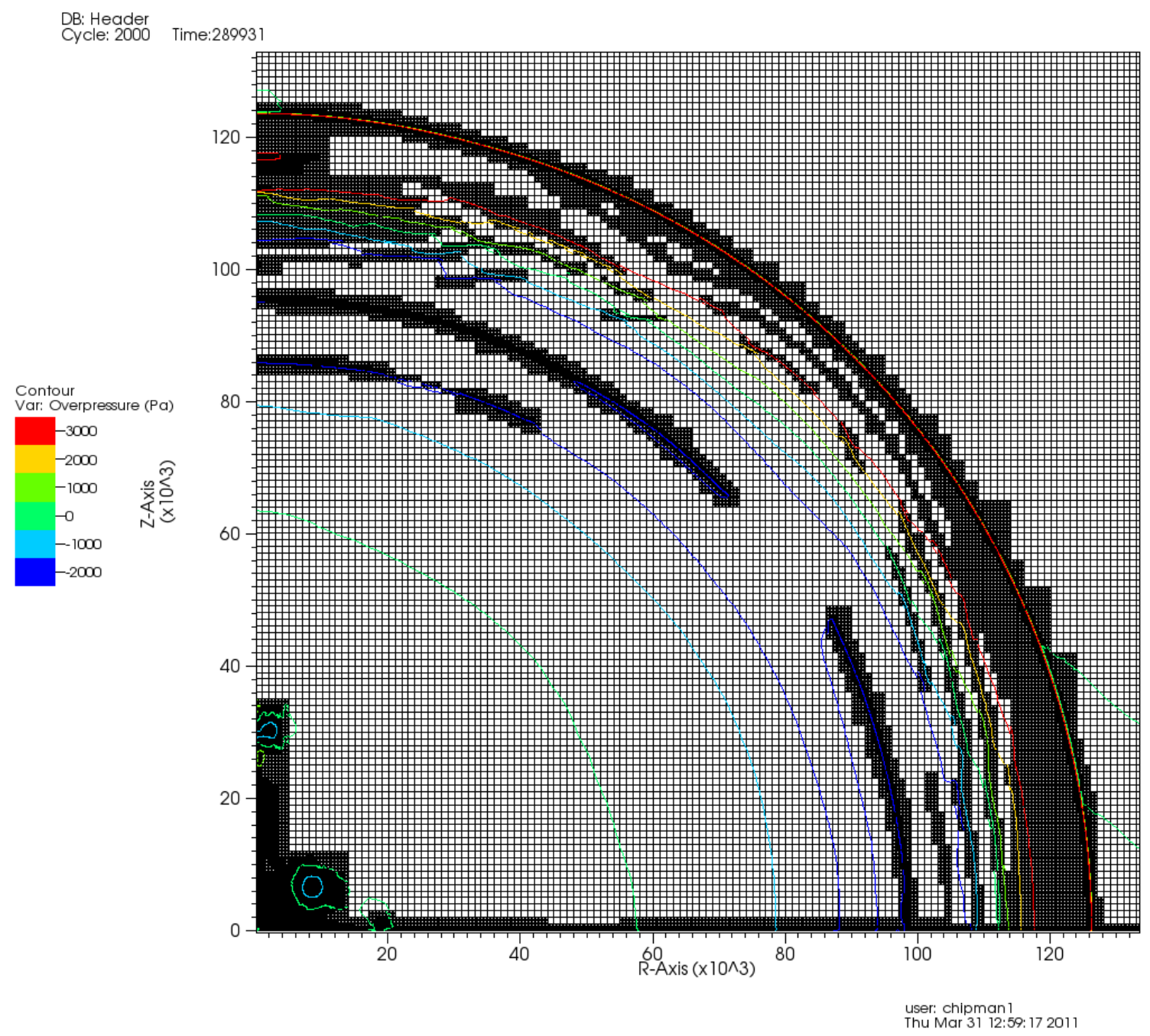

Figure 7: Mesh refinement for the HR-1 GEODYN model at Time=0.289931 s. The "blackened" area represents the highest level of mesh refinement.

\section{Modeling Results}

Each shot was modeled using the yield parameters outlined in Table 3. The arrival of the first impulse was adjusted to coincide with that of the data recorded by the respective pressure sensor at the ranges shown in Table 1 by effectively adjusting the bulk speed of sound in the atmosphere. The atmospheric sound speed was calculated from the environmental data using the standard equation:

$$
a=\sqrt{\gamma \cdot R \cdot T}
$$

where

$$
\begin{aligned}
& a=\text { speed of sound }(\mathrm{m} / \mathrm{s}) \\
& \gamma=\text { ratio of specific heats for the medium }=1.4 \text { for standard air }
\end{aligned}
$$




$$
\begin{aligned}
& R=\text { gas constant }=287 \mathrm{~J} / \mathrm{kg} \cdot \mathrm{K} \\
& T=\text { temperature in degrees Kelvin }
\end{aligned}
$$

As shown in Table 4, the calibrated sound speeds matched those calculated from the environmental conditions summarized in Table 2 within approximately 1\%. Figures 8 through 14 show plots of overpressure versus time for Shots A through G. Note that for Shot A reliable pressure data was not recorded, so the arrival of the first impulse was based solely on the sound speed calculated from the atmospheric data reported in Table 2. Also note that because of the depth of burial for Shot G, a SHAMRC model was not calculated for that particular shot (Marrs et al. 2009). Additionally, the peak overpressure and positive phase impulse was calculated for each shot by importing the test data and the GEODYN overpressure results into MathCad. Those values are summarized in Tables 5 and 6, and the impulses plotted in Figure 15.

With the exception of Shots A (for lacked reliable pressure data) and G (deeply enough buried to not a produce a significant impulse), the GEODYN model was able to accurately simulate the overpressure response due to an explosion at varying heights or depths of burst. The magnitude of the first positive overpressure peak for each of the GEODYN models had a slightly higher magnitude than that of the respective recorded data. As well, the positive phase impulses (i.e. the integration of the first positive peak from its breakthrough time to the time it changes sign) were slightly higher, but in all matched the recorded test data well. In addition, it would appear that from the comparisons of Shots D and G (1.5 and 5 meters DOB, respectively), the deeper the depth of burial the more pronounced the differences between the model and the recorded data. It should be noted that the difference in positive phase impulse between the model and the recorded data falls within the uncertainty reported earlier in the yield of the chemical explosive. The accuracy of the model in predicting the characteristics of the air blast are therefore directly coupled to the uncertainty of the yield as determined by the material properties of the explosive source, and thus represents a limit to the accuracy of the model.

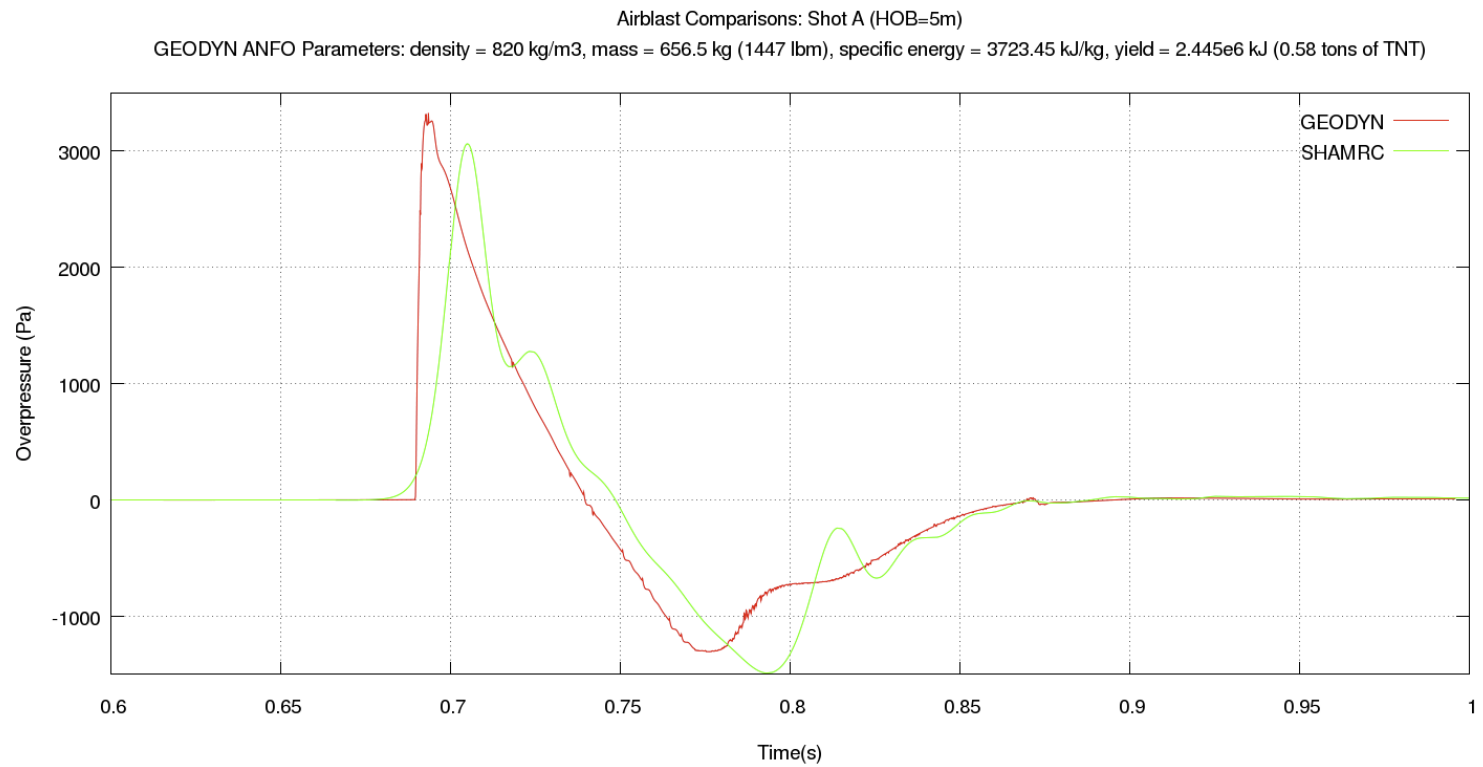

Figure 8: Overpressure versus time for Shot A. 


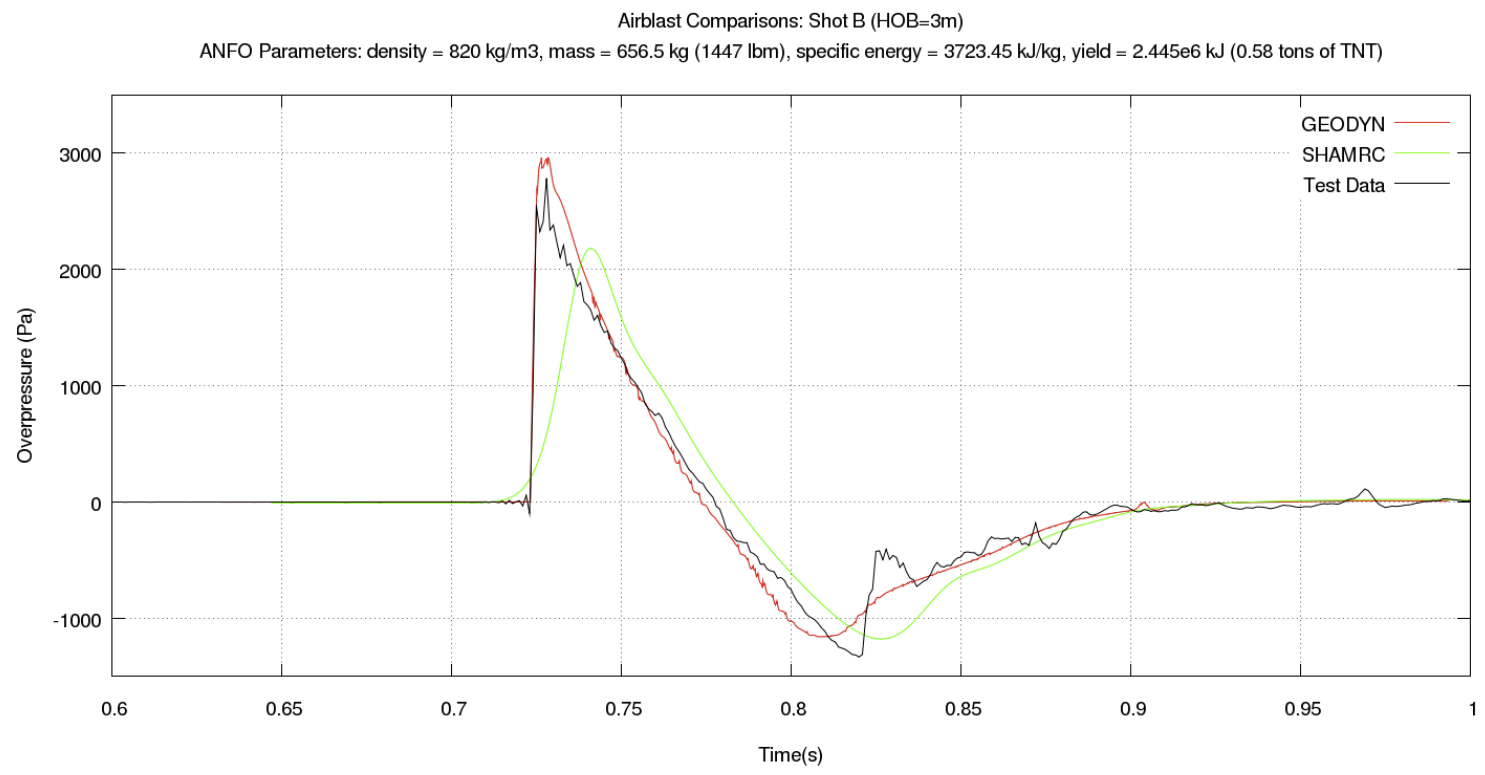

Figure 9: Overpressure versus time for Shot B.

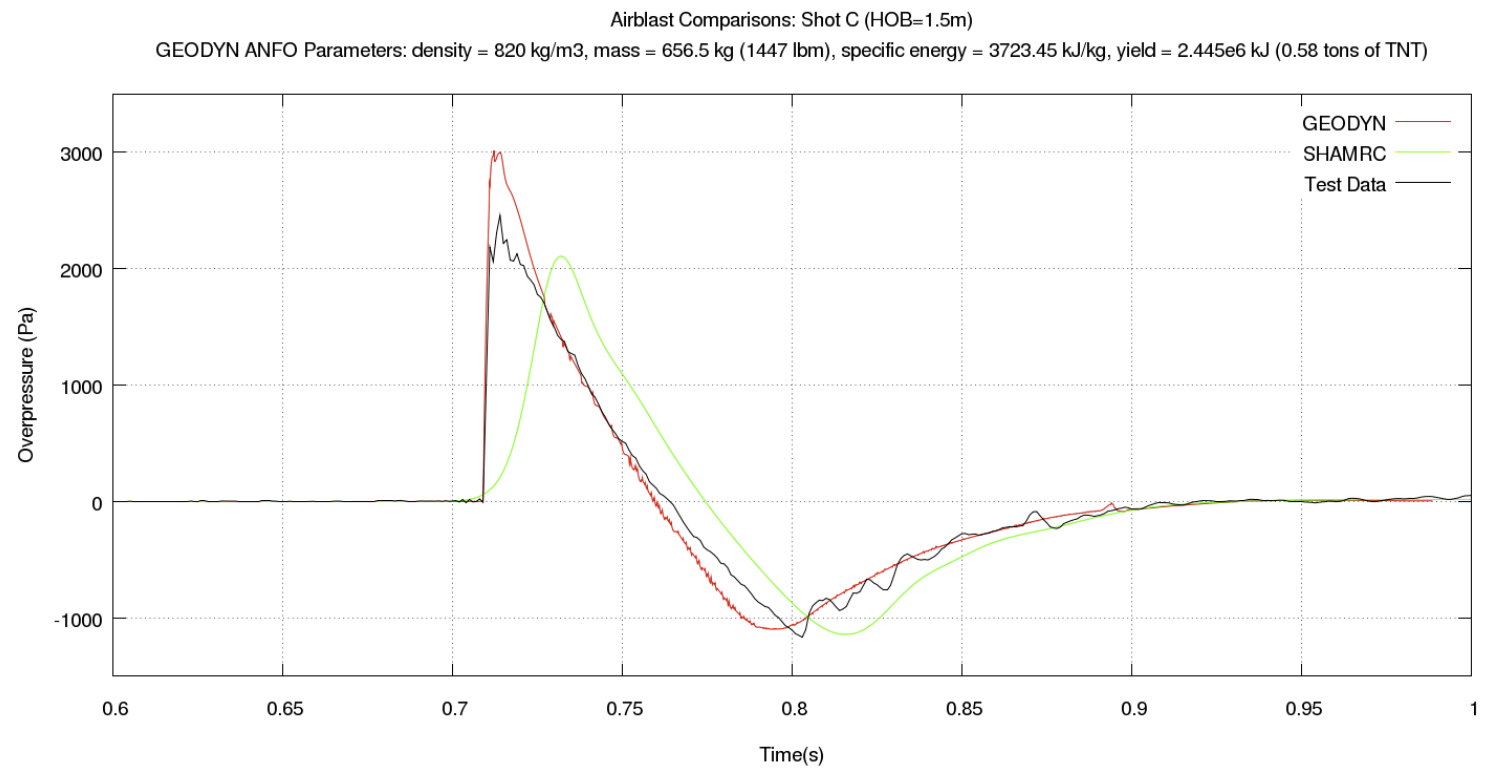

Figure 10: Overpressure versus time for Shot C. 


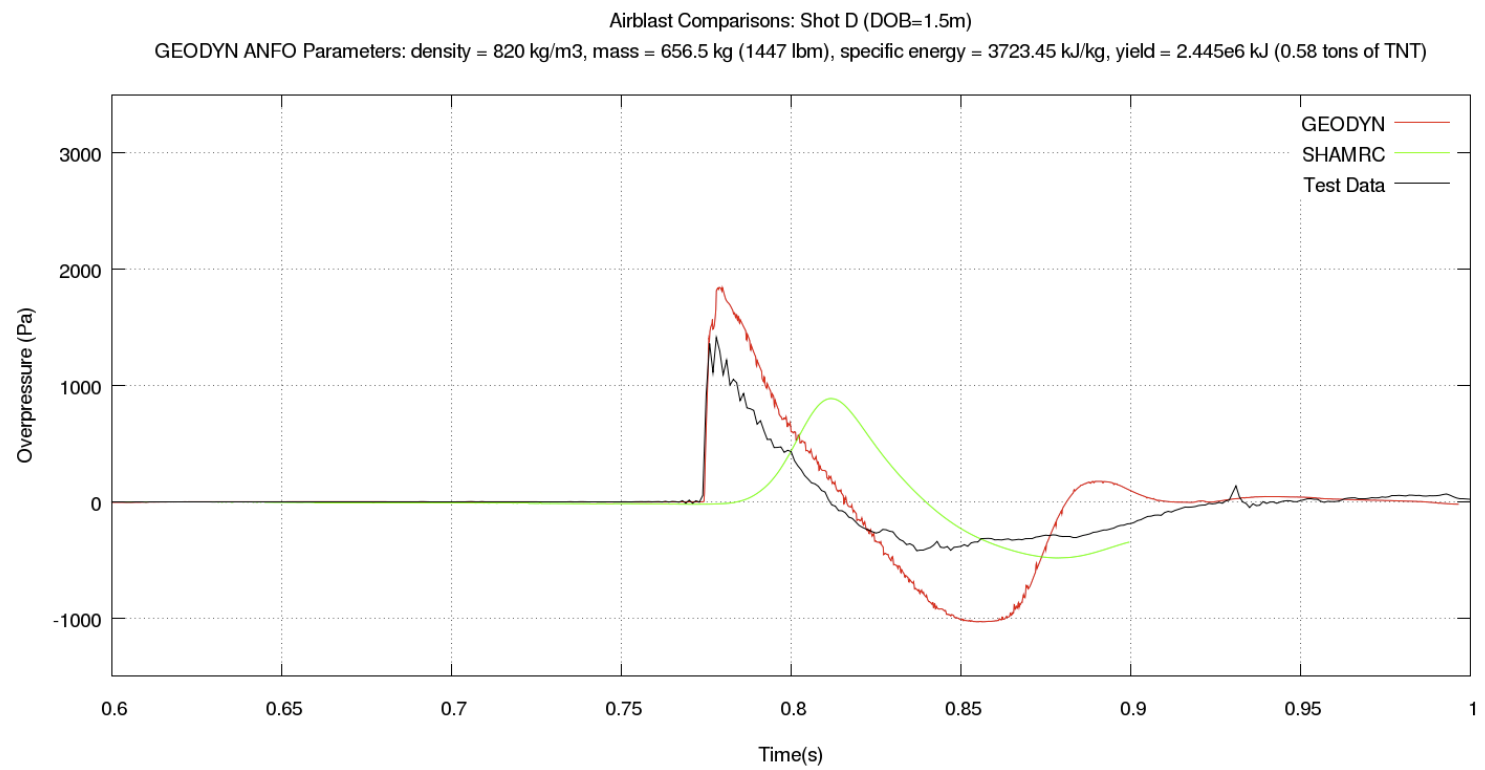

Figure 11: Overpressure versus time for Shot D.

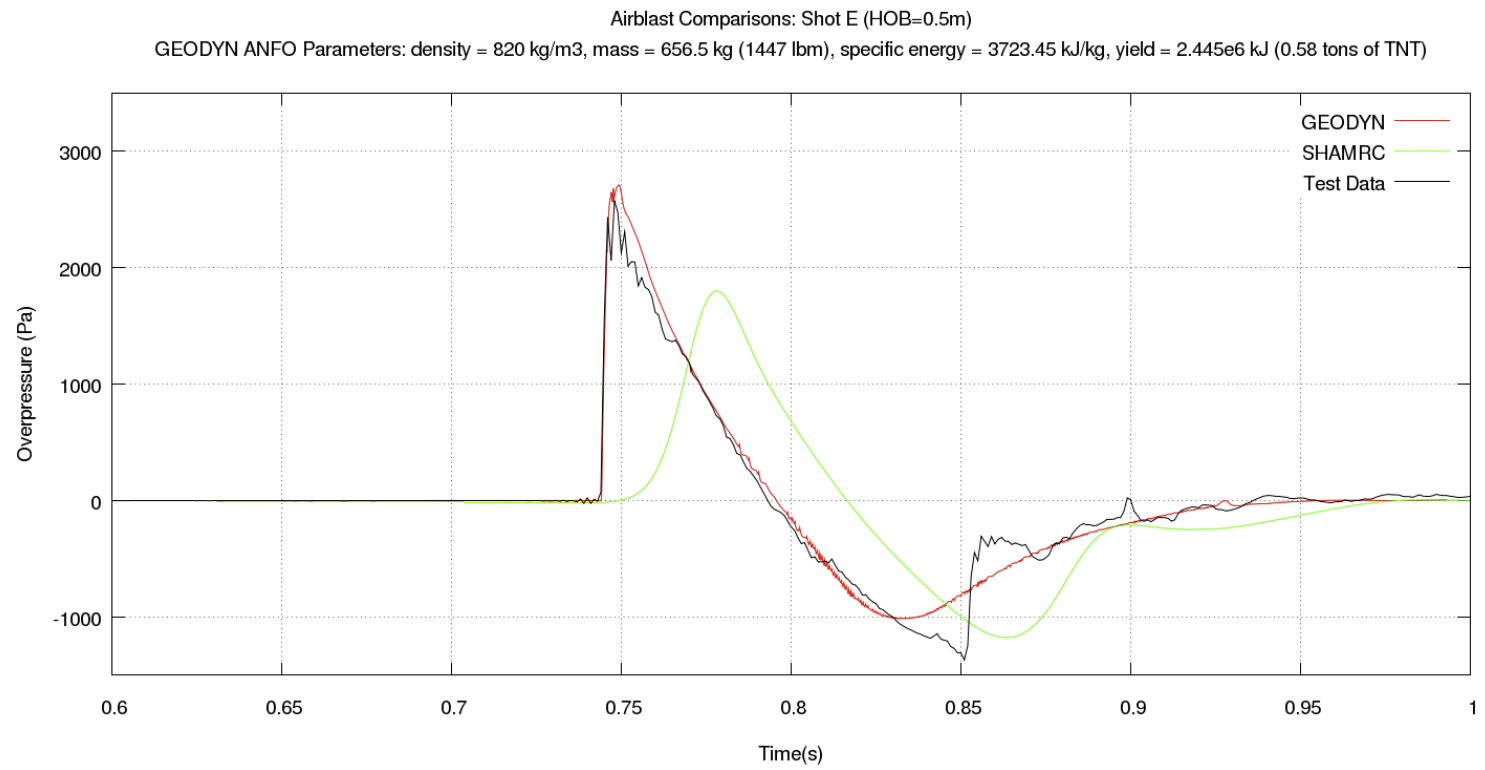

Figure 12: Overpressure versus time for Shot E. 
Airblast Comparisons: Shot $\mathrm{F}(\mathrm{DOB}=0.5 \mathrm{~m})$

GEODYN ANFO Parameters: density $=820 \mathrm{~kg} / \mathrm{m} 3$, mass $=656.5 \mathrm{~kg}(1447 \mathrm{lbm})$, specific energy $=3723.45 \mathrm{~kJ} / \mathrm{kg}$, yield $=2.445 \mathrm{e} 6 \mathrm{~kJ}(0.58$ tons of TNT)

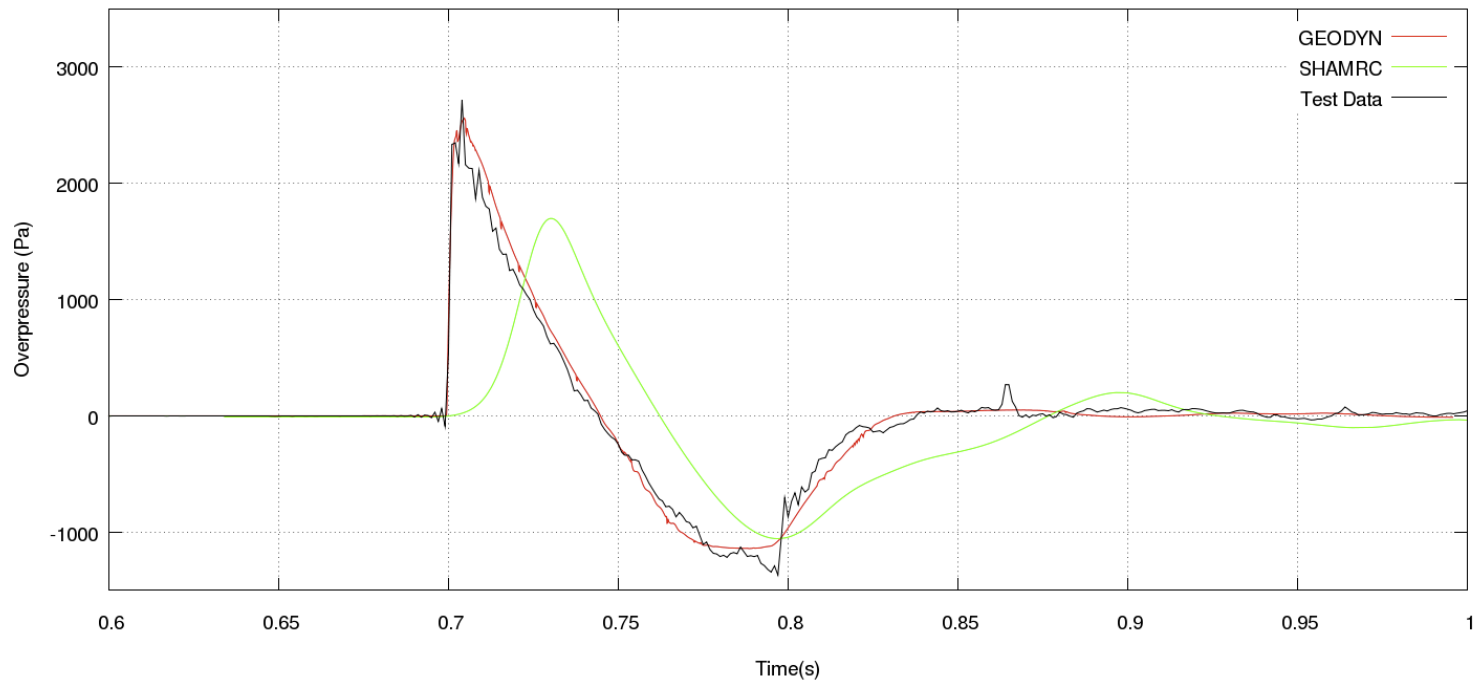

Figure 13: Overpressure versus time for Shot F.

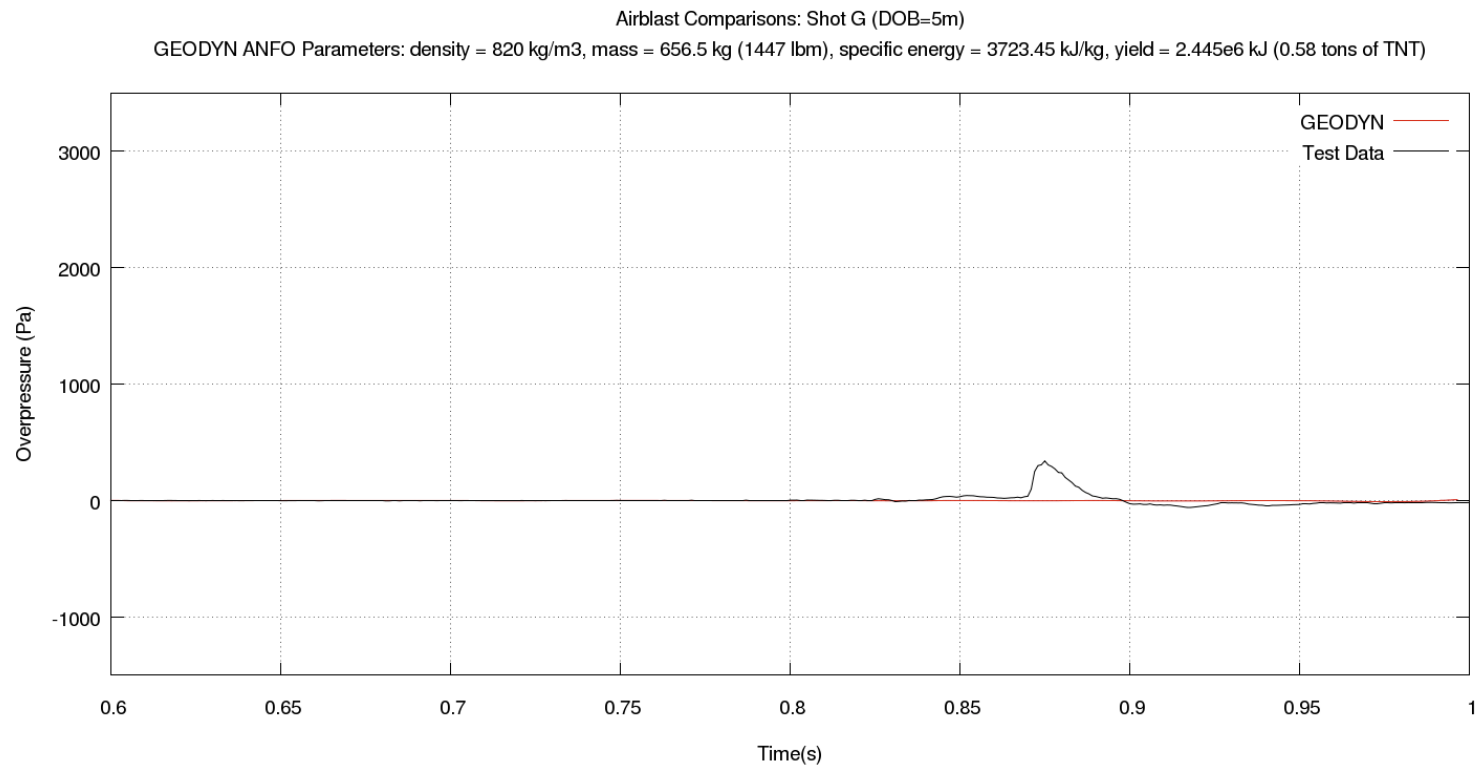

Figure 14: Overpressure versus time for Shot G. 
Table 4: Sound Speeds

\begin{tabular}{|c|c|c|c|}
\hline \multirow[b]{2}{*}{ Shot } & \multicolumn{3}{|c|}{ Sound Speed $(\mathrm{m} / \mathrm{s})$} \\
\hline & $\begin{array}{c}\text { Based on Recorded } \\
\text { Environmental Conditions } \\
\qquad(\gamma=1.4)\end{array}$ & GEODYN & $\%$ Error \\
\hline A & 349.81 & 349.81 & N/A \\
\hline $\mathrm{B}$ & 347.02 & 343.94 & $0.89 \%$ \\
\hline $\mathrm{C}$ & 350.00 & 346.30 & $1.06 \%$ \\
\hline $\mathrm{D}$ & 345.15 & 342.81 & $0.68 \%$ \\
\hline $\mathrm{E}$ & 347.47 & 346.75 & $0.21 \%$ \\
\hline $\mathrm{F}$ & 346.44 & 345.07 & $0.40 \%$ \\
\hline $\mathrm{G}$ & 348.69 & N/A & $\mathrm{N} / \mathrm{A}$ \\
\hline
\end{tabular}

Table 5: Peak Overpressures

\begin{tabular}{|c|c|c|c|}
\cline { 2 - 4 } \multicolumn{1}{c|}{} & \multicolumn{3}{c|}{ Peak Overpressures (Pa) } \\
\hline Shot & Test Data & GEODYN & \% Error \\
\hline B & 2783.6 & 2961.1 & $-6.4 \%$ \\
\hline C & 2458.2 & 3015.1 & $-22.7 \%$ \\
\hline D & 1414.0 & 1844.0 & $-30.4 \%$ \\
\hline E & 2574.4 & 2710.5 & $-5.3 \%$ \\
\hline F & 2717.4 & 2559.6 & $5.8 \%$ \\
\hline
\end{tabular}

Table 6: Positive Phase Impulses

\begin{tabular}{|c|c|c|c|}
\cline { 2 - 4 } \multicolumn{1}{c|}{} & \multicolumn{3}{c|}{ Positive Phase Impulse (Pa·s) } \\
\hline Shot & Test Data & GEODYN & \% Error \\
\hline B & 65.6 & 69.5 & $-5.9 \%$ \\
\hline C & 63.1 & 64.7 & $-2.5 \%$ \\
\hline D & 23.5 & 35.6 & -51.5 \\
\hline E & 58.6 & 62.2 & $-6.1 \%$ \\
\hline F & 50.0 & 50.8 & $-1.6 \%$ \\
\hline
\end{tabular}

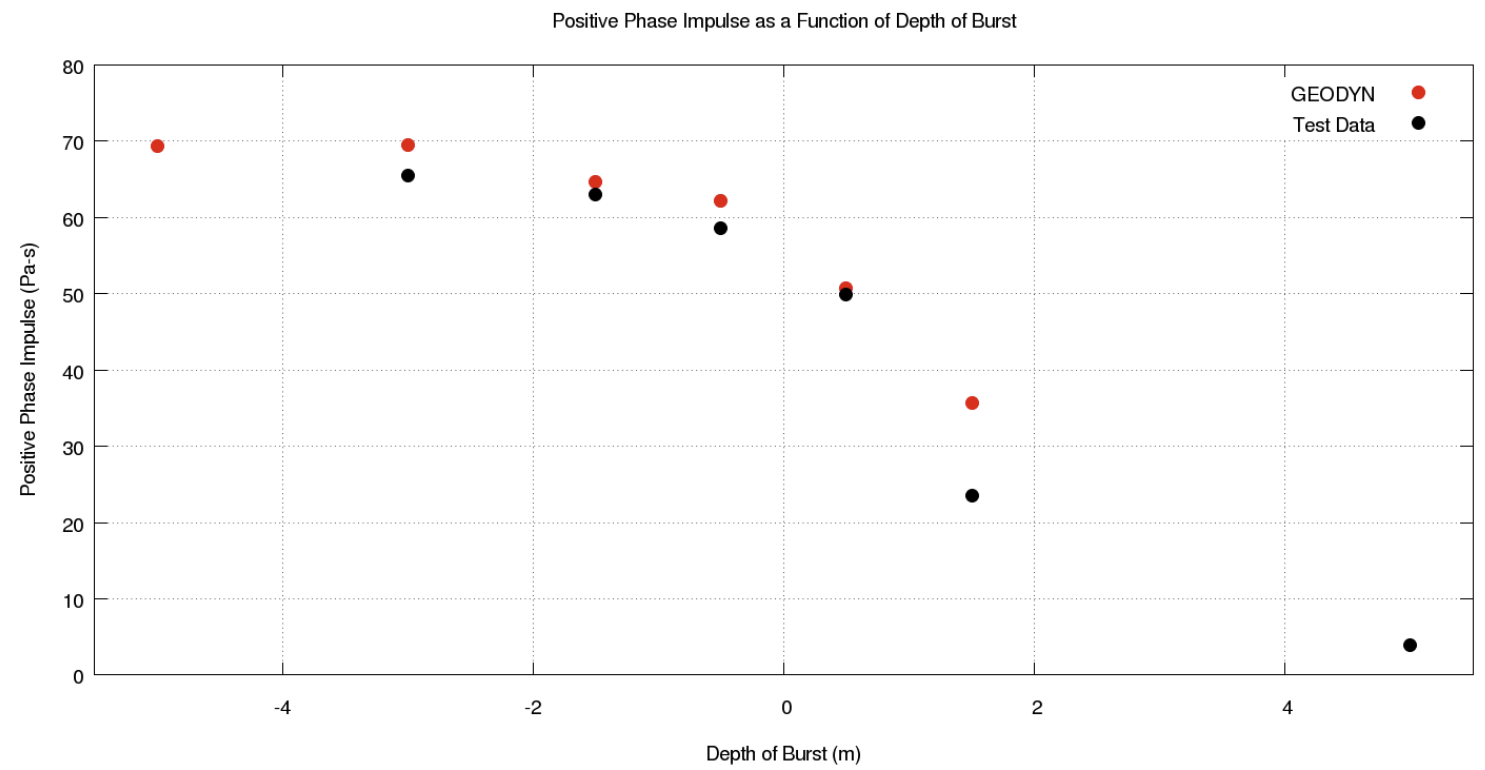

Figure 15: Positive phase impulse as a function of depth of burst for Shots B through F (a negative depth of burst indicates $=$ a height of burst ). 


\section{Conclusions}

GEODYN was able to accurately simulate both the overpressure responses and the positive phase impulses for the series of Humble Redwood I chemical high explosive detonations. The limit to the accuracy of the model is directly coupled to the uncertainty in quantifying the material properties of the chemical explosive that make up the yield. The results of the modeling showed that with an appropriate mesh refinement scheme, GEODYN was able to predict the breakthrough as well as the shape of the actual overpressure response for an above ground detonation and shallowly buried shots. GEODYN appears to be a more than adequate tool to model an air blast, and it appears feasible to use air blast data posteriori in a GEODYN model in conjunction with other pieces of forensic information to ascertain the yield and height or depth of burst of an explosive detonation.

\section{Acknowledgements}

The author wishes to acknowledge the contributions made to this work by Heming $\mathrm{Xu}$, Oleg Vorobiev, Ilya Lomov, Ross Marrs, Bill Foxall, and Artie Rodgers.

This work performed under the auspices of the U.S. Department of Energy by Lawrence Livermore National Laboratory under Contract DE-AC52-07NA27344.

\section{References}

Marrs, R., W. Foxall, O. Walton, R. Reinke, D. Seastrand, 2009, Calculations and Measurements of Air Blast Propagation from the Humble Redwood High Explosive Detonations, LLNLTR-420437.

Foxall, W., R. Marrs, A. Ramirez, D. Templeton, O. Vorobiev, O. Walton, 2011, Final Report Urban Yield, LLNL-TR-471537.

Vorobiev, O., Yu., 2008, Generic Strength Model for Dry Jointed Rock Masses, International Journal of Plasticity, 24, 2221*2247. 